\title{
Implementing Change and Planning English Corequisite Classes
}

\author{
Mary Ellen Young \\ Melisa Jones
}

\section{ABOUT THE AUTHORS}

Mary Ellen Young is the Dean of Liberal and Performing Arts and Honors College at Texarkana College. She is President-Elect for the Texas Community College Teachers Association and has twenty-eight years of teaching experience in English and/or reading in public schools and higher education.

Lisa Jones is the Director of Texarkana Adult Education and Coordinator for Developmental Education at Texarkana College. She is the Membership Chair for the Texas Association of Developmental Education. An educator for twenty-five years, she has taught high school and college English and worked with developmental students.

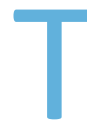

exarkana College (TC) was first introduced to corequisite English classes in 2011 at the Achieving the Dream Conference through the Community College of Baltimore County's Accelerated Learning Program (ALP) (Venezia \& Hughes, 2013). Acceleration reduces the time and/or course sequence in developmental education (DE), allowing students to enroll in gateway courses more quickly and/or co-enroll in the first college-level English course while taking the remedial course (Venezia \& Hughes, 2013). TC faculty piloted the ALP with a 12:1 student-teacher ratio and then increased to $15: 1$ and took the plunge to scale up to full implementation to make it cost-effective for the college. Fifteen students enroll in the Integrated Reading and Writing II course and in the Composition I course with the same instructor. Ten additional students who qualify for Composition I join the fifteen students who are co-enrolled in Composition I. The English faculty have been included throughout the process, including the piloting phase and in creating common syllabi for both courses. Other important factors for consid-

eration include logistics such as course loads, room availability, scheduling, course criteria, registration coding, and collaboration with enrollment management and advising (Adams \& McKusick, 2014).

One challenge has been the ability to code the courses on the schedule to determine enrollment in both courses so that it is clearly understood by students and enrollment services. With the assistance of division and enrollment management personnel, corequisite courses are listed by section with a $\mathrm{P}$ for paired for each section: ENGL 0042.P1-Cap of 15 students; ENGL 1301.P1-Cap of 15 students (same 15 enrolled in ENGL 0042.P1), and ENGL 1301.01Cap of 10 regular Composition I students. To streamline communication of placement for students, the testing center, enrollment services, and faculty advisors color coded testing sheets and placement charts. A portion of lab time was also incorporated into the schedule during instructional time rather than expecting students to navigate lab assignments independently. Another challenge has included difficulties with student passcodes and technical problems associated with English labs manufactured and packaged by textbook companies. Therefore, faculty created a departmental English lab in the college's Learning Management System. Students no longer have to purchase lab access, and the lab instruction, quizzes, and assignments can be adjusted and modified to meet the needs of the students. A common course syllabus is also used by all instructors for each course, complementing the curriculum in each course and building and reinforcing reading and writing skills in the Integrated Reading and Writing course.

Teaching methods in the course rely heavily on active and collaborative learning techniques such as peer groups, peer editing, think-pair-share, and group projects and presentations. Innovative teaching methods include writing a comparison and contrast essay based on an in-depth peer interview. Also, students write an argumentative group research paper that requires collaboration on choosing a topic, researching the topic, writing and correctly using MLA documentation.

The course's success has been demonstrated through data as well as student and faculty reaction. In fall $2015,78 \%$ of students enrolled in the corequisite model were successful in English 0042 and seventy-four percent were successful in English 1301. In fall 2016, 83\% of students were successful in English 0042 and 82\% were successful in English 1301. Students are appreciative of the ability to accelerate their completion of DE English while also completing the gateway course. Professors find value in the extended class time with students because of the rapport established with the students. Faculty and staff at TC have realized the benefits of students taking a DE course for skills improvement. 


\section{References}

Adams, P., \& McKusick, D. (2014). Steps and missteps:

Redesigning, piloting, and scaling a developmental writing program. New Directions for Community Colleges, 2014(167), 15-25. doi: 10.1002/ cc. 20107

Venezia, A., \& Hughes, K.L. (2013). Acceleration strategies in the new developmental education landscape. New Directions for Community Colleges, 2013(164), 37-45. doi: 10.1002/cc.20079 